\title{
Erratum to: Potential relationship between single nucleotide polymorphisms used in forensic genetics and diseases or other traits in European population
}

\author{
Maria Pombar-Gomez ${ }^{1}$ - Elixabet Lopez-Lopez ${ }^{1}$ - Idoia Martin-Guerrero ${ }^{1}$. \\ Africa Garcia-Orad ${ }^{1,2}$ - Marian M. de Pancorbo ${ }^{3}$
}

Published online: 1 August 2015

(C) Springer-Verlag Berlin Heidelberg 2015

Erratum to: Int J Legal Med (2015) 129:435-443

DOI 10.1007/s00414-015-1165-7

The original version of this article, unfortunately, contained an error.

Africa Garcia-Orad's name was incorrectly captured as Africa Garcia-Orad Carles; thus, resulting to Carles AG in indexing sites and when cited.

The correct name is now given in this article.

The online version of the original article can be found under doi:10.1007/ s00414-015-1165-7.

Marian M. de Pancorbo

marian.mdepancorbo@ehu.es

1 Department of Genetics, Physical Anthropology and Animal Physiology, Faculty of Medicine and Odontology, University of the Basque Country (UPV/EHU), Leioa, Spain

2 BioCruces Health Research Institute, Bilbao, Spain

3 BIOMICs Research Group, Centro de Investigación "Lascaray" Ikergunea, University of the Basque Country (UPV/EHU), Avda. Miguel de Unamuno 3, 01006 Vitoria-Gasteiz, Spain 